\title{
Noves INSCRIPCIONS ROMANES D’EDETA (LLÍRIA, VALÈNCIA)
}

FRANCISCO DE MANUEL RIOJA ${ }^{1}$, FERRAN ARASA I GIL ${ }^{\circledR}$, XAVIER VIDAL FERRÚS ${ }^{3}$

(1) Arqueòleg. Programa de doctorat en Geografia i Història del Mediterrani. Universitat de València. info@arqueoico.com

(2) GRAM. Dpt. Prehistòria, Arqueologia i $\mathrm{H}^{\mathrm{a}}$ Antiga. Universitat de València. Ferran.Arasa @uv.es

(3) Museu Arqueològic de Llíria. mall@lliria.es

Presentem dues noves inscripcions trobades en el curs de sengles intervencions arqueològiques portades a terme en els darrers anys al municipi romà d'Edeta. Es tracta d'un epígraf funerari i d'un fragment d'inscripció de caràcter monumental on figura un magistrat municipal ${ }^{1}$.

\section{INSCRIPCIÓ FUNERÀRIA}

Es trobà en l'excavació realitzada al mes de juliol de l'any 2016 en un solar del carrer Enric Valor, situat al N de la població (De Manuel 2016; De Manuel et al. en premsa). Les principals troballes arqueològiques foren una estructura negativa de forma allargada, tal vegada una canalització d'aigües que continua per altres solars en direcció $\mathrm{N}$ i es perd a la vora d'un testar de la mateixa cronologia (s. I a.C.); i un pou votiu (UE 1006) excavat en el nivell geològic constituït per roca calcària, semblant a molts altres trobats en aquesta població, en el qual aparegué la inscripció. La seua planta era circular, amb $84 \mathrm{~cm}$ de diàmetre i una profunditat de 5,06 m. El rebliment estava format per terra i pedres amb abundants restes de fauna, alguns objectes de bronze i ferro, altres de vidre i nombrosa ceràmica que data majoritàriament del s. I d.C. La datació del darrer nivell de rebliment pot situar-se en el s. III d.C. En aquest aparegué un carreu que, quan es va extraure, es va comprovar que era el suport d'una inscripció funerària que es troba en un excel·lent estat de conservació (fig. 1).

Es tracta d'una llosa de calcària d'Alcubles de color blau fosc (fig. 2). La cara frontal està finament polida, mentre que els laterals estan desbastats i la posterior és irregular. El camp epigràfic és llis. Al costat esquerre, en les parts central $\mathrm{i}$ inferior hi ha una zona blanquinosa amb la superfície un poc desgastada que afecta a la primera lletra de les línies 3 i 4 . Els extrems d'algunes lletres tenen petits trencalls als esvorancs, $i$ altres han patit erosions que no en dificulten la lectura: la $F$ del final de la primera línia, la $R$ de la tercera i la segona $I$ de la sisena. L'ordinatio està centrada al voltant d'un eix, però és irregular en la part dreta d'algunes línies com la segona, cinquena i sisena, en aquest cas per ser més llarga. La lletra és de factura acurada i elegant, de solc estret i poc profund, amb reforços; en les línies 5-6 el solc és més ample i profund i en la darrera canvia el ductus i la lletra és més 


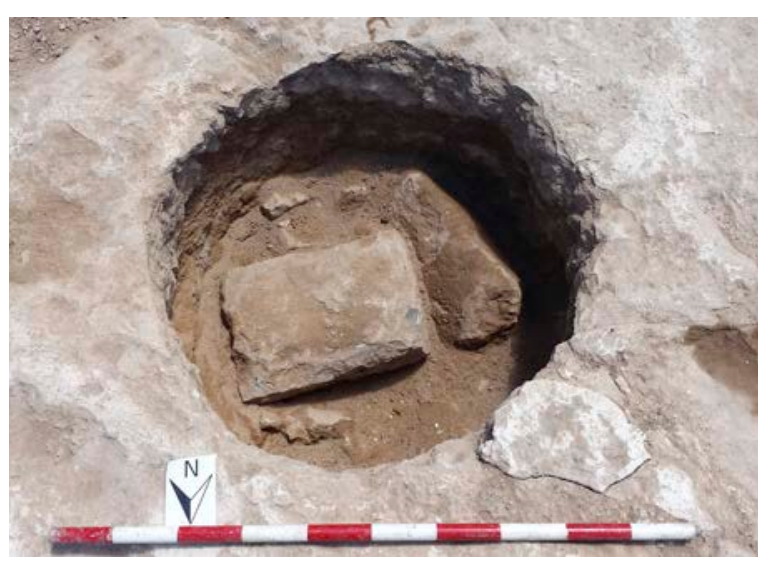

Fig. 1: Pou votiu (UE 1006) de l'excavació al carrer Enric Valor amb la inscripció a l'interior.

estilitzada. L'altura de les lletres és major en la primera línia i un poc més petita i prou regular en la resta. Les dues $Q$ dels prenoms que figuren en les línies 1 i 3 són un poc més grans i la $T$ de la sisena línia és un poc més alta. Hi ha una intrusió de $S$ dins de $O$ al final de la cinquena línia, i un nexe d'AN en l'edat de la sisena. Les interpuncions són triangulars, petites i amb un extrem orientat cap avall en les línies 1-5 i cap amunt en la sisena. Es conserven les línies de guia en la meitat dreta i sobretot al final d'algunes línies; la superior de la tercera està esmenada i és doble.

Dimensions $=30,5 \times 44 \times 13 \mathrm{~cm}$.

Marges $=$ superior: $3,2 \mathrm{~cm}$; inferior: $1,5 \mathrm{~cm}$; esquerre: 1,7 ; dret: $0 \mathrm{~cm}$.

Interlineació = 1-2) $1 \mathrm{~cm}$; 2-3) $1,3 \mathrm{~cm}$; 3-4) $1 \mathrm{~cm}$; 4-5) $1 \mathrm{~cm}$; 5-6) $0,3 \mathrm{~cm}$.

Altura de les lletres = 1) $4-4,5 \mathrm{~cm}$;) $3 \mathrm{~cm}$;) 3-3,8 $\mathrm{cm}$;) $3 \mathrm{~cm}$;) $3 \mathrm{~cm}$; 6) $3,5 \mathrm{~cm}$.

\section{$Q$ (uintus) Minicius $Q$ (uinti) f(ilius)}

Navos an(norum) XXV h(ic) s(itus) e(st).

$Q$ (uintus) Minicius Urbanus

Domitia Buccula

5 uxor sibi et filios.

L(ucius) Min(icius) Maritumus an(norum) XXX.

La lectura del text no presenta cap dificultat, atés que es troba en bon estat de conservació. Es tracta d'un epitafi múltiple, de caràcter familiar. Un matrimoni format per Q. Minicius Urbanus i la seua esposa Domitia Buccula el dedica al seu fill $Q$ (uintus) Minicius $Q$.f.Navos, mort als

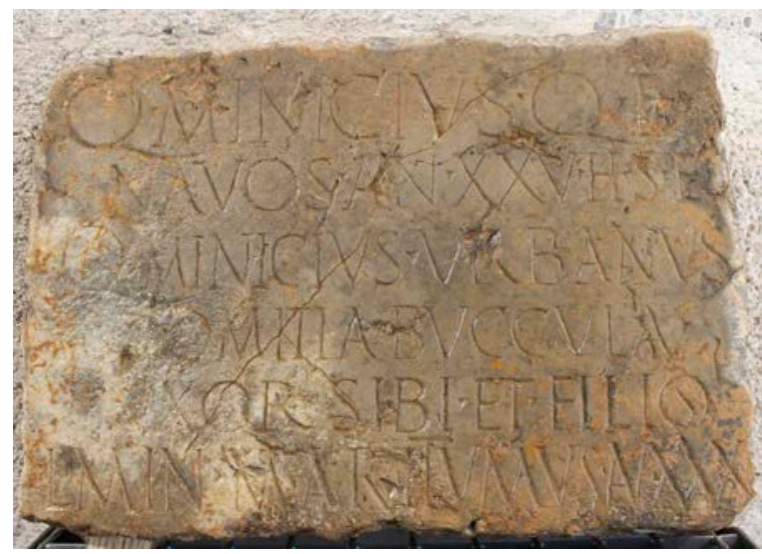

Fig. 2: Inscripció funerària.

25 anys, i per a si. Posteriorment s'afegeix una darrera dedicatòria al segon fill, L. Min(icius) Maritumus, mort als 30 anys, i llavors s'inclou una $S$ en la $O$ de filio per a obtenir la desinència de l'acusatiu plural.

Alguns dels noms dels difunts resulten de particular interés. En primer lloc, el gentilici Minicius/a (Solin i Salomies 1994: 119) no és molt freqüent a Hispània (Abascal 1994: 185-186). En terres valencianes el trobem en un cas a la mateixa ciutat d'Edeta (IRPV IV, 57; CIL II $^{2}$ 14, 164): M. Minicius[s] Hermes; i en altres dos a Oliva i la Font d'en Carròs (la Safor), ací en un personatge que exercí totes les magistratures a la seua ciutat (IRPV VI, 187 i 191). En canvi, Domitius/a és molt freqüent per tot l'Imperi (Solin i Salomies 1994: 69; Abascal 1994: 129131). Pel que fa als cognoms, Navos és escàs: a l'EDCS figura en tres ocasions, dues a Roma i una a Bavay (Bèlgica); altres cognoms relacionats igualment escassos són Anavos/Annavos i Canavos. No es coneix a Hispània, tot i que amb la forma Navus hi apareix en dos casos, un a Artés (Barcelona) i l'altre a Portugal (Solin i Salomies 1994: 367; Abascal 1994: 436). Urbanus és un cognom freqüent per tot arreu. Buccula és molt estrany (Solin i Salomies 1994: 225, 498) i no es troba a Hispània; sí que hi apareix Bucco/a en vuit casos (Abascal 1994: 305), tres dels quals a Velilla de Ebro (Saragossa). A l'EDCS el trobem en 16 ocasions, en la seua majoria a Bèlgica i Aquitània. Finalment, Maritumus/a és molt poc freqüent (Solin i Salomies 1994: 353), i es troba en dos casos a Hispània (Abascal 1994: 415), un dels quals a Valentia (IRPVV, 100). Sí que ho és més Maritimus/a, que trobem a Hispània en vuit casos, un d'ells a Xèrica (l'Alt Palància) (IRPV II, 35). 
L'ús del nominatiu en els noms dels difunts, la paleografia i el camp epigràfic llis aconsellen una datació en el s. I d.C.

\section{INSCRIPCIÓ MONUMENTAL}

Aparegué en l'excavació arqueològica realitzada a l'estiu de 2018 al solar situat a l'avinguda del Pla de l'Arc, 2, que fa cantonada amb el carrer J. Pérez Palanca, al nord del santuari i les termes de Mura, al centre de la ciutat romana. Aquesta zona va ser emprada com a terreny de cultiu en les èpoques medieval i moderna, i el material petri dels edificis romans es va reutilitzar en la construcció de sèquies $\mathrm{i}$ abancalaments com l'aparegut en l'excavació, fet molt freqüent en els ss. XVI i XVII. En la intervenció aparegué la roca a escassa profunditat, que estava rebaixada formant diverses estructures negatives com fronts de pedrera, fosses, etc, entre les quals destaquen dues cambres subterrànies amb galeria que foren amortitzades en època andalusina. També es trobà un tram d'una conducció subterrània d'època romana que comptava amb diverses entrades i cambres en galeria associades. A meitat solar aparegué un abancalament (UE 1037) orientat nord-sud i construït amb grans carreus travats amb morter de calç, que conservava dues filades amb una longitud de $270 \mathrm{~cm}$, una altura màxima de 50 $\mathrm{cm}$ en la seua meitat nord i una amplària de $45-53 \mathrm{~cm}$, del qual formava part la inscripció (fig. 3).

És un fragment de calcària beix de procedència local que formava part d'un element arquitectònic (fig. 4).

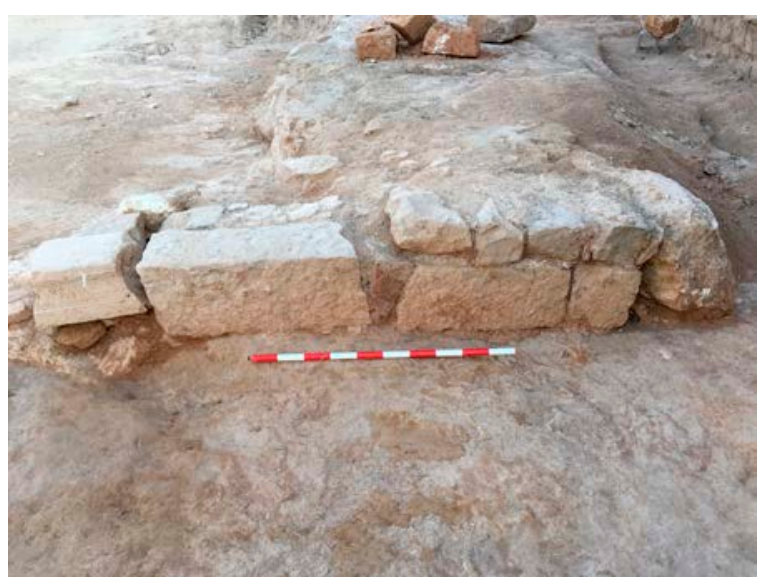

Fig. 3: Abancalament (UE 1037) trobat en un solar situat a l'avinguda del Pla de l'Arc, amb la inscripció situada a l'esquerra.
Està trencat per tots els costats excepte pel superior, que presenta una superfície allisada que devia servir d'assentament per als carreus del coronament del monument al qual pertanyia, de tipus desconegut. La inscripció es troba en un plànol rebaixat cenyit per les parts superior $\mathrm{i}$ inferior per motlures de $2,5 \mathrm{~cm}$ d'altura, a les quals segueixen dues bandes llises, la superior -l'única que es conserva íntegra- de $5 \mathrm{~cm}$ d'altura, que conserven les empremtes de treball. El camp és llis i té $8 \mathrm{~cm}$ d'altura. La lletra és de factura acurada però un poc irregular, de solc ample i profund, amb reforços. La $I$ i la $V$ són un poc més petites. Només es conserva un punt en forma d'hedera distinguens de $3 \mathrm{~cm}$ d'altura.

Dimensions $=(24) \times(42) \times(37) \mathrm{cm}$.

Marges $=$ superior: $1,7 \mathrm{~cm}$; inferior: $2 \mathrm{~cm}$.

Altura de les lletres $=4-4,5 \mathrm{~cm}$.

$$
\text { [--- Ma]ximus } \cdot \text { ae[d(ilis) ---] }
$$

La part conservada del text no presenta cap dificultat de lectura. A l'esquerra es veu el reforç inferior d'una lletra que deu ser una $A$. En segueixen 5 més que pertanyen a un cognom que pot restituir-se amb moltes probabilitats com [Ma]ximus. A continuació de l'hedera es veuen dues lletres que corresponen al començament d'un mot, la segona de les quals és una $E$ afectada per la fractura en els extrems dels seus braços. Per la posició que ocupa, a continuació d'un cognom, pot restituir-se amb moltes probabilitats com una magistratura municipal que, com és frequient, figuraria abreviada: aed(ilis). El text devia

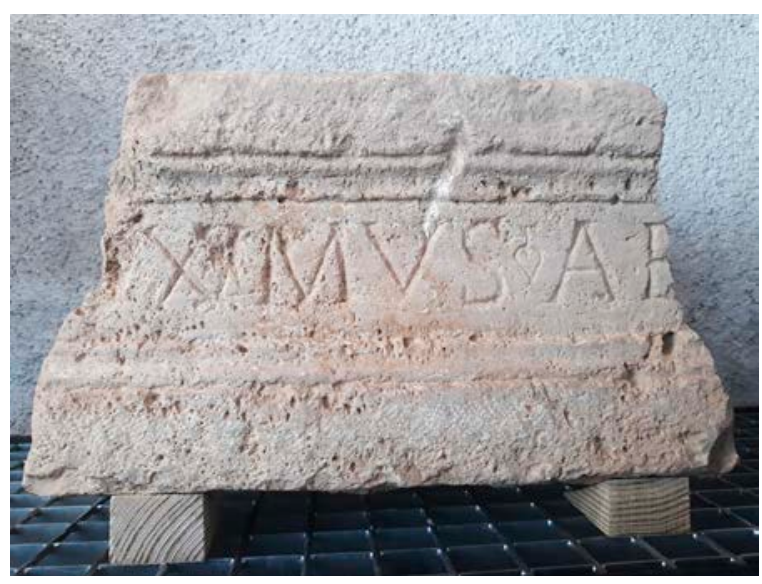

Fig. 4: Inscripció monumental. 
ser considerablement més llarg, ja que per l'esquerra falta la resta del nom: el prenom abreviat, el nomen, la filiació, tal vegada la tribu i el principi del cognom; i per la dreta possiblement altres magistratures municipals i tal vegada alguns honors. Es tractava, doncs, d'un magistrat municipal.

El cognom Maximus/a no és massa freqüent (Solin i Salomies 1994: 361). Al País Valencià està representat en alguns casos, en particular a Saguntum, Valentia, Edeta i Ilici (Abascal 1994: 421-423). A Edeta el trobem en tres epígrafs, un dels quals (IRPV IV, 11; CIL II $\left.{ }^{2} 14,130\right)$-incomplet i desaparegut- degué correspondre a un membre de l'orde eqüestre, del qual no tenim constància que exercira magistratures municipals: [---] L.f. Gal. Maxim[o / ---]m prae[f(ecto) C[---]. Entre els set ciutadans edetans que van exercir magistratures municipals, només d'un es diu que assolí els honors edilicis: L. Cornelius L. F. Gal. Potitus honor(ibus) aedil(icis) functo (IRPV IV, 14; CIL II ${ }^{2}$ $14,131)$. Entre les magistratures fins ara documentades en aquest municipi trobem un aedilis, un quaestor, un IIII vir, dos II viri, quatre flamines i un personatge que va rebre [omnib(us) honor(ibus ci]vitatis su[ae func] to (IRPV IV, 12-18; CIL II² 14, 131-134 i 136-137). Es tracta, doncs, del segon cas en què apareix un edil i el primer en què figura expressament mencionada aquesta magistratura.

Resulta impossible determinar el tipus de monument a què pertanyia el fragment. Només es pot apuntar que l'altura de les lletres, entre 4 i 4,5 cm, sembla reduïda per a ser vista de lluny. Tanmateix, per les seues característiques i el tenor del text sembla pròpia d'un fris o de la llinda d'una porta. En aquest sentit, podem recordar que les lletres de la inscripció de la porta del possible aedes augusti del fòrum de Valentia mesuren 5,5-6,5 cm d'altura (Corell i Gómez 2007: 321; Escrivà et al. 2013: 5960 ), de manera que no pot descartar-se aquesta possibilitat. Com el fragment conserva una part tan reduïda del text tampoc se'n pot copsar el sentit amb seguretat: per tractar-se d'un magistrat municipal podria tractar-se de l'epistili d'un monument erigit per ell en l'exercici de les seues funcions, però també podria ser un monument honorífic o funerari dedicat a ell per la seua família o pel municipi. Finalment, la paleografia i l'ús de l'hedera en la puntuació aconsellen una datació en el s. II d.C.

\section{BIBLIOGRAFIA}

ABASCAL, J. M. (1994): Los nombres personales en las inscripciones latinas de Hispania, Murcia.

CORELL, J.; GÓMEZ, X.: Dos inscripciones monumentales del foro de Valentia, Acta XII Congressus Internationalis Epigraphiae Graecae et Latinae, Barcelona, 324-325, Ed. CD-Rom.

DE MANUEL RIOJA, F. (2016): Informe preliminar. Intervención arqueológica parcelas 6A, 6B y 6C C/ d'Enric Valor (antes de Julià Palanca) U. E. 3 del P.G.O.U. de Llíria, $n^{\circ}$ exp. 2016/0135-V(SS.TT.: 0700P.15), Benissanó.

DE MANUEL, F.; SANTFELIU, D.; SANCHO S.; PITARCH, A. (e.p.): El pou votiu romà del carrer d'Enric Valor de Llíria (València), V Jornades d'Arqueologia de la Comunitat Valenciana, València, 2016.

EDCS = Epigraphik-Datenbank Clauss/Slaby: http://www.manfredclauss.de/ (12/04/2019).

ESCRIVÀ, M. I.; JIMÉNEZ SALVADOR, J. L.; RIBERA, A. (2013): La curia y la basílica de Valentia, Las sedes de los ordines decurionum en Hispania. Análisis arquitectónico y modelo tipológico (B. Soler et al., eds.), Anejos de AEspA LXVII, 53-67.

IRPV II = CORELL I VICENT, J. (2005): Inscripcions romanes del País Valencià. II. 1. L’Alt Palància, Edeba, Lesera i els seus territoris. 2. Els mil·liaris del País Valencià, València.

IRPV IV = CORELL I VICENT, J. (2008): Inscripcions romanes del País Valencià. IV. (Edeta i el seu territori), València.

$I R P V$ V = CORELL I VICENT, J. (2009): Inscripcions romanes del País Valencià. V. Valentia i el seu territori, València.

IRPV VI = CORELL I VICENT, J. (2012): Inscripcions romanes del País Valencià. VI. (Ilici, Lucentum, Allon, Dianium i els seus territoris), València.

SOLIN, H.; SALOMIES, O. (1994): Repertorium nominum gentilium et cognominum latinorum, Olms-Weidmann.

\section{NOTA}

1. Volem agrair als professors J. M. Abascal (UA) i J. L. Jiménez (UV) l'atenció que han posat a les nostres consultes. 